\title{
Как преодолеть стагнацию и восстановить экономическое развитие
}

А.Г. АГАНБЕГЯН, академик РАН, зав. кафедрой Российской академии народного хозяйства и государственной службы при Президенте РФ, Москва

В статье автор анализирует причины, которые привели экономику России к стагнации и рецессии. Предложены меры для восстановления социальноэкономического развития страны - форсированные инвестиции и подъем экономики знаний.

Ключевые слова: экономика России, рецессия, стагнация, инвестиции, экономическая политика, инфляция

- Абел Гезевич, в свое время Вы создавали журнал «ЭКО» как «мост» между учеными-экономистами и практикамихозяйственниками. Удалось ли в полной мере реализовать эту концепциию?

- Мне кажется, что за первые 10 лет работы «ЭКО» мы приблизились к решению этой задачи. Журнал в определённой мере стал настольной книгой для многих хозяйственников, его подписчиками были более 180 тыс. человек, и он был самым массовым изданием среди экономических журналов в стране.

Сейчас такое вряд ли возможно, но это не означает, что к этому не надо стремиться. Я бы предложил аналитически проработать вопрос: какого рода публикации сегодня полезны аудитории журнала, разделив их по приоритетности. Нужно также подумать и о наилучших формах подачи материалов.

Мы переживаем тяжёлые времена в социально-экономической сфере, и, естественно, хозяйственников в первую очередь интересуют вопросы выживания и возможности развиваться в этих условиях, а главное - как преодолевать трудности, с которыми сталкиваемся?

Когда от рецессии и стагнации мы перейдём к социальноэкономическому развитию, эти задачи во многом изменятся. И нужно быть готовыми разработать новые приоритеты тематики с большим креном в инновационное развитие, наращивание человеческого капитала, проектные инвестиции, особенно в высокотехнологичные отрасли. 
- Bы входите в круг признанных экспертов Правительства. Насколько восприимчивы действующие руководители страны $\kappa$ советам экспертов?

Известны ли Вам в мировой практике случаи, когда ученые могли оказывать влияние на экономические процессы?

- Мне кажется, что у нас отсутствует традиция регулярного общения высших руководителей, принимающих решения, с экспертами. У таких руководителей, естественно, есть помощники и советники, но социально-экономическая область настолько обширна, что нужно иметь группу советников, а не одного-двух, как у нас. В США, например, при президенте страны есть целый Совет советников, члены которого еженедельно общаются с президентом, и их суждения оказывают самое серьёзное влияние на экономическую политику.

Во время своих многочисленных поездок в США и в советское время, и в новой России в 1990-е и в начале 2000-х годов я общался с отдельными советниками, часть из которых знал как ведущих профессоров крупных университетов США. Один из них был специалистом по экономике СССР (а потом и России) и обычно говорил по-русски, был хорошо знаком с нашей статистикой, публикациями, различными предложениями. И советники старались встречаться с нашими специалистами, приезжавшими в США, чтобы узнать что-то новое, обсудить интересующие их вопросы.

В качестве яркого примера коллективной деятельности этой группы советников приведу разработку ими новой экономической политики США - «рейганомики», которая вывела эту страну из затянувшейся на десятилетие в 1970-х - начале 1980-х гг. стагнации и рецессии вместе с тяжёлым процессом стагфляции. Эти негативные тренды не смогли преодолеть президенты Генри Форд и Джимми Картер, которые не были переизбраны на второй срок, что нечасто наблюдалось в США.

Были значительно снижены налоги и увеличены стимулы инвестирования в экономику, вдвое снижены нормы амортизации и дана возможность ускоренного износа фондов, что привело к массовому технологическому обновлению народного хозяйства и развитию высокотехнологичных и инновационных отраслей. Это дало импульс мощному 25-летнему социальноэкономическому развитию США вплоть до кризиса 2007-2009 гг. 
США преодолели наметившееся инновационное отставание от Японии и серьёзно укрепили свой статус ведущей экономической державы мира с самым высоким уровнем экономического и социального развития.

Если взять примеры нашей страны, то наибольшее влияние на экономические процессы оказала группа учёных-единомышленников во главе с Е.Т. Гайдаром, которая в 1992 г. спасла страну от экономической катастрофы, гиперинфляции и распада, заложив основы перехода от централизованной административной системы к рыночному хозяйству. Такая возможность им была предоставлена Президентом России Б.Н. Ельциным, который сформировал из этих ученых Правительство.

Серьёзное влияние на экономическую политику оказали на рубеже 1990-х и 2000-х гг. разработки Центра стратегических инициатив во главе с Г.О. Грефом: на их основе был составлен Бюджетный кодекс, сформирована новая пенсионная система, начаты реформы в образовании и здравоохранении. Разработчики программ из Центра стратегических инициатив, созданного по инициативе В.В. Путина, заняли ряд ключевых мест в Правительстве РФ и могли добиваться результата, занимая руководящие позиции.

Определённое воздействие на решения Правительства РФ и сегодня оказывают разработки Института экономической политики им. Е. Т. Гайдара и исследовательских групп из РАНХиГС и ВШЭ. Им, как известно, в 2011 г. было поручено разработать «Стратегию социально-экономического развития страны-2020», проект которой рассматривался и в Правительстве, и у Президента.

Важнейшее положение этой стратегии - о повышении доли инвестиций во внутренний валовый продукт до 25\% к 2015 г. было внесено В. В. Путиным в его Указ от 7 мая 2012 г. «О долгосрочной экономической политике». Однако этот Указ не был выполнен Правительством, которое, напротив, начало сокращать инвестиции с 2013 г., что стало одной из причин перехода страны к стагнации (задолго до событий на Украине, санкций, снижения цен на нефть), девальвации рубля, взлёту инфляции и повышению ключевой ставки ЦБ РФ.

- Почему Россия попала в стагнацию и рецессию после трехлетнего успешного экономического развития в 2010-2012 г2., 
когда удалось восстановить и превзойти докризисные показатели в экономике и социальной сфере?

- Один важнейший фактор, связанный с политикой инвестиций, я назвал. Инвестиции в кризис 2009 г. сильно снизились (на 16\%), и поэтому в последующие годы (больше всего в 2013 г.) наблюдались слабый прирост основных фондов и недополучение из-за этого значительной части товаров. В связи с неправильной инвестиционной политикой в 2012-2013 гг. государственные инвестиции значительно сократились, и их снижение не смогло перекрыть даже увеличение частных инвестиций. ЦБ и Правительство к тому же ничего не сделали, чтобы увеличить объёмы инвестиционного кредитования, из-за чего снизилась текущая экономическая активность в 2013 г. В результате промышленность остановилась, упали объёмы экспорта, строительства, ухудшились финансовые результаты деятельности предприятий и организаций. Началась стагнация.

«Беда не приходит одна»: недостаток инвестиций и низкий ввод основных фондов усугубились возникшим в кризис 2008-2009 гг. оттоком капитала, который продолжается уже девятый год. Сократилась и экспортная выручка. И хотя предприятия и организации России, имея свободный доступ на финансовый рынок страны, нарастили свой долг иностранным инвесторам в 2012-2013 гг. более чем на 190 млрд долл., взяв на Западе и в Китае непомерно большие займы, это не спасло нашу экономику от недофинансирования экономического роста и потянуло её вниз.

Нехватка инвестиций привела к снижению коэффициентов выбытия основных фондов и их обновления. Они стали прогрессивно устаревать. Коэффициент износа приблизился к 50\% в целом по народному хозяйству, а по отдельным отраслям достиг 70\%. Средний срок службы машин и оборудования возрос до 14 лет, вдвое превысив данный коэффициент в передовых странах. У нас $22 \%$ машин и оборудования и сегодня продолжают работать свыше сроков износа. Увеличились затраты на их ремонт, обслуживание. Возросли простои устаревшей техники и всё это тоже потянуло экономику страны вниз.

И последний из главных факторов - отсталая структура нашей экономики, где гипертрофирована доля топливно-энергетических и сырьевых отраслей, производства полуфабрикатов и материалов и крайне низка доля высокотехнологичных отраслей и сферы 
экономики знаний, которые в других странах являются главными локомотивами развития.

Со второй половины 2014 г. возникли новые негативные условия - были введены санкции против России в связи с присоединением Крыма и событиями на Украине, в 2,5 раза снизились цены на нефть, рубль девальвировался вдвое по отношению к доллару и евро. В результате в 2014 г. значительно снизился внешний товарооборот страны, впервые стали сокращаться реальные доходы, а также инвестиции и объём строительства, почти до нуля упали темпы роста ВВП.

А с 1-го квартала 2015 г. началась рецессия, т. е. прямое падение ВВП, промышленности, строительства, транспорта, инвестиций, реальных доходов и потребления населения, начался рост безработицы, значительно увеличилась бедность. Из-за удвоения цен на импортные товары в связи с девальвацией рубля утроились годовые темпы инфляции (с 5,1\% в 2012 г. до свыше 15\% в 2015 г.), до небывалых размеров возросла ключевая ставка Банка России, началось снижение объёма кредитования, и экономика покатилась вниз. В 1-м квартале 2015 г. ВВП снизился на 2,2\%, во 2-м - на 4,6\% и в 3 -м - на 4,1\% по отношению к соответствующему периоду 2014 г.

Особенность этой рецессии состоит в том, что масштабы сокращения доходов и потребления населения вдвое больше по сравнению с экономическими показателями: за январь-октябрь 2015 г. по отношению к 2014 г. ВВП снизился на 3,8\%, промышленность - на 3,3\%, инвестиции - на 5,7\%, в то время как конечное потребление домашних хозяйств - на 9\%, реальная заработная плата - на 9,3\%, розничный товарооборот - на 8,8\%. Впервые после 2005 г. снизилась рождаемость и выросла смертность, увеличилась заболеваемость. Доходы и потребление населения, а также демографические показатели выглядят намного хуже, чем в кризис 2008-2009 гг.

Из экономических показателей наибольшее падение продемонстрировали объёмы внешней торговли - сокращение на треть как по экспорту, так и по импорту.

По прогнозу ЦБ России, МВФ и Всемирного банка, 2016 г. также будет годом рецессии: ВВП сократится на 1-2\%, инвестиции - на 3-4\%, реальные доходы - на 3\%. И при продолжении 
существующей политики 2017 и 2018 гг, скорее всего, будут годами стагнации.

- Что необходимо сделать, чтобы преодолеть рецессию и стагнацию и восстановить социально-экономическое развитие?

- По мнению большой группы экспертов-экономистов, надо менять экономическую политику.

1. Перейти к форсированным инвестициям с ежегодным их приростом по 8-10\% с тем, чтобы повысить долю инвестиций в основной капитал до $25 \%$ в 2020 г. и $30 \%$ (как в среднем в развивающихся странах) - в 2025 г.

Одновременно надо на 8-10\% в год наращивать человеческий капитал в России, для чего следует обеспечить подъём экономики знаний (НИОКР, образование, информационные технологии, биотехнологии и здравоохранение). По развитию экономики знаний, которая в России создаёт только $15 \%$ ВВП, мы катастрофически отстаём от Западной Европы (35\% ВВП) и США (40\% ВВП).

Ведь экономика знаний - главный локомотив в развитии современной экономики, и она должна расти в 1,5-2 раза быстрее ВВП, в то время как в последний период в России она увеличивается медленнее ВВП и становится не локомотивом, а тормозом нашего развития.

2. Форсированные инвестиции и подъём экономики знаний обязательно должны быть подкреплёны значительным снижением инфляции и ключевой ставки ЦБ до 3-4\%. На это может потребоваться три года. Сделать такой рывок чрезвычайно трудно, и самостоятельно Центральному банку это вряд ли удастся, поэтому целесообразно разработать специальную Президентскую программу, которую нужно осуществлять под жёстким контролем совместными усилиями Правительства и Банка России. Нужно предотвратить попытки государственных и олигархических монополий повысить тарифы, установив мораторий на государственные цены, и развить конкурентную среду в стране. Содействовать этому могла бы и отмена антисанкций. Надо стимулировать установление низких цен на продукцию и услуги, повысив налогообложение тем организациям, которые реализуют строящееся жильё по высоким ценам, а также гостиницам, торговым сетям, объединениям по оказанию услуг, которые продают товары и услуги по завышенным ценам. И, напротив, 
снизить налоги при продаже жилья экономкласса, в магазинах с низкими ценами и т. п.

3. Нацелить использование возрастающих инвестиций главным образом на технологическое обновление действующего производства (со сроком окупаемости - 5-7 лет), на ввод новых производственных мощностей для высокотехнологичных отраслей (срок окупаемости - 10-12 лет), на создание современной транспортно-логистической инфраструктуры с переходом к массовому строительству автострад и скоростных железных дорог (с окупаемостью в 20-25 лет), для удвоения жилищного и связанного с ним социально-бытового строительства к 2020 г. (срок окупаемости - 2-4 года), для подъёма всей сферы экономики знаний.

При объёме инвестиций 2015 г. в размере около 13 трлн руб. (19\% ВВП) в существующих ценах и условиях речь идёт о дополнительных инвестициях в размере около 9 трлн руб. при общем их объёме 22 трлн руб. (30\% ВВП).

По нашим оценкам, на каждое из направлений по технологическому обновлению действующего производства, вводу новых мощностей в высокотехнологичных отраслях и созданию современной транспортно-логистической инфраструктуры потребуется дополнительно по 2 трлн руб. в год, а на жилищно-социальное строительство и на подъём экономики знаний - по 1,5 трлн руб.

4. Главным источником дополнительных инвестиций могли бы стать активы нашей банковской системы, которые в 2014 г. превысили объём ВВП России. В настоящее время из примерно 72 трлн руб. банковских активов на инвестиционный кредит идёт всего 1,1 трлн руб. (1,5\%). Из всех инвестиций доля инвестиционного кредитования составляет у нас только 9\% (в США, Германии и других развитых странах - 30-50\%, а в Китае и других развивающихся странах - более $20 \%$ ).

Следовало бы повысить долю инвестиционного кредита в активах банков до 4\%, что обеспечило бы на обозримый период 8-10\%-й прирост инвестиционных средств в год.

Чтобы превратить «короткие» деньги банковских активов в «длинные» инвестиционные, нужно по примеру многих других стран делать это за счёт выпуска Казначейством для покрытия 3\%-го дефицита бюджета долговременных ценных бумаг, которые смогут по низкой годовой процентной ставке 
(например, 3-4\%) приобретать ЦБ, ВЭБ, Агентство по ипотечному кредитованию и, возможно, другие крупные фонды. У них будут формироваться долгосрочные пассивы, и под залог этих ценных длинных бумаг они могли бы, добавляя небольшую свою маржу (например, $0,5 \%$ ), по низким ставкам кредитования предоставлять средства надёжным коммерческим банкам для финансирования предприятий, готовых осуществлять на выгодные заёмные средства технологическое обновление, создание новых высокотехнологичных производственных мощностей, жилищносоциальное строительство и др. Казначейство США выпускает такие казначейские обязательства на 40-летний период, а банк Японии - даже на 50 лет. Думаю, что для России достаточно было бы выпускать долгосрочные ценные бумаги Казначейством сроком до 25 лет.

Современный годовой дефицит бюджета составляет около 3 трлн руб., из которых Центральный банк мог бы приобрести 1,5 трлн руб., Внешэкономбанк - 1 трлн, Агентство по ипотечному кредитованию - 0,5 трлн руб. В большой выгоде будет Казначейство, которое ежегодно сможет получать значительную маржу от этих средств; для ЦБ также будет выгодно иметь дополнительные средства по столь низкой ставке и тоже получать маржу без значительных усилий. Получение крупных долговременных займов улучшит условия заимствования и для коммерческих банков.

Для быстроокупаемых инвестиций можно было бы взаимообразно использовать и часть золотовалютных резервов (например, 170 млрд долл. из объёмов международных золотовалютных резервов), превысивших 370 млрд долл.

При реализации предложения В.В. Путина об освобождении инвестиций за счёт средств организаций и предприятий от налогообложения и мер по сокращению сроков амортизации можно было бы изыскать дополнительно 1 трлн руб. инвестиций за счёт собственных средств предприятий и организаций.

При переходе к реальной приватизации в России госпредприятий и организаций, не выполняющих государственных функций, а занимающихся коммерческой деятельностью для получения прибыли и самообогащения (АвтоВАЗ, значительная часть организаций «Газпрома», «Роснефти», «Ростехнологии», Сбербанка, ВТБ и т. д., включая госпредприятия и организации 
в регионах и муниципалитетах), можно было бы использовать на взаимообразных началах значительную часть средств, полученных при приватизации, на инвестиционные кредиты.

Население страны накопило сбережений около 25 трлн руб. в России и, по оценкам, до 700 млрд долл. - за рубежом. Использование даже небольшой части этих сбережений на инвестиционные цели, особенно на строительство жилья, приобретение земельных участков под дачное строительство, покупку автомобилей, могло бы дать значительный источник средств для развития соответствующих отраслей. Для этого следует создать более выгодные приоритетные условия для покупки жилья и автомобиля с более высокой долей использования собственных средств граждан, которые соответствующие организации на выгодных условиях могли бы направить на инвестиционные цели.

Наконец, при необходимости можно было бы прибегнуть к крупным займам, прежде всего, у международных финансовых организаций, со стороны нашего государства, чей внешнеэкономический долг минимальный, а имидж аккуратного плательщика долгов - крайне высок.

Ставка на прирост инвестиций за счёт возвратного инвестиционного кредита является наиболее эффективным способом дополнительного инвестирования с точки зрения целевого использования этих средств и их возврата Центральному банку, Внешэкономбанку, другим государственным фондам.

5. Ввести действенные стимулы для экономического роста в соответствии с предложениями, высказанными Президентом РФ В.В. Путиным на Санкт-Петербургском международном экономическом форуме в 2014 г.: налоговые, таможенные, кредитные и другие стимулы при технологическом обновлении производства, создание производственных мощностей в высокотехнологичных отраслях, развитие всех сфер экономики знаний, импортозамещения, при производстве на экспорт готовой продукции с высокой добавленной стоимостью, для сокращения нашей зависимости от экспорта нефти и газа, широко ввести проектное финансирование.

6. Крайне важно органически подкрепить дополнительное финансирование и экономический рост необходимыми институциональными преобразованиями (структурными реформами), устраняющими препятствия на этом пути. Речь идёт об усилении 
конкурентной среды, о предотвращении необоснованного увеличения цен, снятии административных преград и препятствий для бизнеса, всемерном развитии государственно-частного партнёрства, повышении экономической ответственности и прав регионов и муниципалитетов и многом другом. Ключевое направление этих преобразований - защита бизнеса и повышение роли частной собственности, её неприкосновенность и возмещение ущерба от каждого действия государственных органов, которое приносит убыток частным собственникам.

\section{$\star \star \star *$}

При осуществлении всех указанных мероприятий среднегодовые темпы роста ВВП, по нашей оценке, достигнут 2\% в 2018 г., $4 \%$ - в 2020 г., $5 \%$ - в 2025 г. и $6 \%$ - в 2030 г.

Этот прирост ВВП будет давать с каждым годом всё возрастающие дополнительные финансовые средства, которые целесообразно использовать на повышение реальных доходов и потребления населения страны с приоритетностью преимущественного роста уровня жизни малообеспеченных семей и сокращения разницы в децильных доходах богатых и бедных с 16 раз в настоящее время до 13 раз к 2020 г., 10 раз - к 2025 г. и восьми раз - к 2030 г. Самое важное здесь - повышение продолжительности жизни с 71-72 лет в настоящее время до 75 к 2020 г., 79 лет - к 2025 г. и 83 лет - к 2030 г. при сокращении разницы между мужчинами и женщинами с 11 до шести лет. В 2,5 раза при этом нужно снизить детскую смертность (до трех на 1000 родившихся) и в четыре раза - смертность населения в трудоспособном возрасте.

При таких темпах Россия войдёт в число развитых стран по уровню экономического развития и основным экономическим показателям к 2030 г., а по уровню социального развития и основным социальным показателям - к 2035 г. 